\title{
Retraction
}

The article titled, "A study of predictive factors of malignancy in thyroid nodules", published in the International Surgery Journal, Volume 5, Issue 12, 2018, Pages 3817-3822, DOI: http://dx.doi.org/10.18203/2349-2902.isj20184712 is being retracted. We received complaint after publication of the article that it's a plagiarized and fabricated work from an unpublished thesis submitted to the university. We contacted the corresponding author Dr. G. Ashok Swaminathan and he agreed to retract the article. 


\title{
Original Research Article
}

\section{A study of predictive factors of malignancy in thyroid nodules}

\author{
P. Umapathy ${ }^{1}$, G. Ashok Swaminathan ${ }^{2 *}$, M. Fathima Farshana ${ }^{1}$, M. Devagi ${ }^{1}$
}

\begin{abstract}
${ }^{1}$ Department of General Surgery, ${ }^{2}$ Department of Plastic Surgery, Rajah Muthiah Medical College and Hospital, Annamalai University, Annamalainagar 608002, Tamil Nadu, India
\end{abstract}

Received: 21 September 2018

Accepted: 20 October 2018

\section{*Correspondence:}

Dr. G. Ashok Swaminathan,

E-mail: ashokgswaminathan@gmail.com

Copyright: () the author(s), publisher and licensee Medip Academy. This is an open-access article distributed under the terms of the Creative Commons Attribution Non-Commercial License, which permits unrestricted non-commercial use, distribution, and reproduction in any medium, provided the original work is properly cited.

\section{ABSTRACT}

Background: Thyroid nodule is a common presentation and requires structured diagnostic approach to ascertain the risk of malignancy and determine appropriate management. The aims of this randomized study is to evaluate potentiate role of thyroglobulin (Tg), thyroid stimulating hormone (TSH), and size of nodule as preoperative indicators of primary well differentiated thyroid cancer (WDTC).

Methods: This is a retrospective Study of 70 cases of colorectal carcinoma analysing incidence, clinicopathological features and outcome after different therapies including surgery, radiotherapy and chemotherapy.

Results: Preoperative Tg with cut-off $>36 \mathrm{ng} / \mathrm{ml}$ is a significant predictor of malignancy. Anti-Tg Ab with cut-off of $3 \mathrm{IU} / \mathrm{ml}$ along with TSH are independent predictors of malignancy.

Conclusions: FNAC and Frozen section study has specificity of 67 and 75\% and sensitivity of 74 and $80 \%$, respectively. Accuracy of FNAC and frozen section study are 71 and $73 \%$, respectively and preoperative thyroglobulin ( $\mathrm{Tg}$ ) with cut-off $>36 \mathrm{ng} / \mathrm{ml}$ is a significant predictor of malignancy.

Keywords: Benign, Malignant, Thyroid nodule, Thyroglobulin

\section{INTRODUCTION}

Thyroid nodule is a common presentation and requires a structured diagnostic approach to ascertain the risk of malignancy and determine appropriate management. ${ }^{1}$ Thyroid nodules can be detected by palpation in $10 \%$ of women and $2 \%$ of men. ${ }^{1}$ The prevalence of thyroid nodules can be $50 \%$ or more if ultrasonography (US) is used. ${ }^{1}$ Although thyroid nodule is a common presentation, thyroid cancer is rare representing $1 \%$ of all cancers. Thyroid cancer has a favorable prognosis and accounts for less than $0.5 \%$ of cancer deaths. ${ }^{2}$ The well differentiated thyroid cancer (WDTC), which includes papillary and follicular cancer, comprises the vast majority $(90 \%)$ of all thyroid cancers. ${ }^{3}$ A thyroid nodule is defined as a discrete lesion within the thyroid gland that is clinically and radiologically distinct from the surrounding thyroid parenchyma. A thyroid nodule can be either a solitary nodule or a dominant nodule in a multinodular gland and can be clinically non-palpable. The non-palpable nodules are usually detected by incidental USG or other imaging studies and are termed incidentalomas and these non-palpable nodules have the same risk of malignancy as palpable nodules. ${ }^{3}$ The risk of malignancy in generalized thyroid swelling is about $3 \%$ and in solitary thyroid nodule it is about $15 \% .{ }^{4}$ The multinodular goiters (MNG), defined as an enlarged thyroid gland with multiple nodules, have historically been thought of as a benign condition with a low risk of associated malignancy, and may be present in up to $4 \%$ of the population in iodine sufficient countries. ${ }^{5}$

The patients with multiple thyroid nodules have the same risk of malignancy as those with solitary nodules. ${ }^{6}$ 
However, one large study found that a solitary nodule had a higher likelihood of malignancy than did a non-solitary nodule $(p<0.01)$, although the risk of malignancy per patient was the same and independent of the number of nodules. ${ }^{7}$

Traditional risk factors for thyroid cancer in a thyroid nodule have been largely clinical and include age, gender, history of radiation exposure, family history of thyroid cancer, and cancer syndromes.

While the data refining the significance of these risks continue to evolve, recent area of research has been on several biochemical factors which are associated with the risk of malignancy in thyroid nodules. ${ }^{8}$ Some of these biochemical factors include levels of serum thyroid stimulating hormone (TSH), thyroglobulin (Tg) and anti TG antibody (Anti-Tg).

Hence, the present study is designed to evaluate the potential role of biochemical factors especially levels of serum TSH, TG and anti-TG as preoperative indicators of thyroid malignancy.

\section{METHODS}

This study was conducted in the Department of General Surgery in Rajah Muthiah Medical College \& Hospital (RMMC\&H), Annamalai University, Annamalainagar, Chidambaram from May 2014 to May 2017 (3 years).

Present study was a prospective, observational study carried out with a sample size 90 patients. This is a prospective study of patients presenting with complaints of thyroid swelling presenting to the Departments of General Surgery in RMMC\&H.

\section{Methodology}

All patients presenting with the thyroid nodules in the age group 18 to 70 years who are willing to participate in the study will be evaluated clinically with detailed history, physical examination, ultrasonography of neck, biochemical tests like thyroid profile (serum TSH, T3 and T4), TSH (0.4-4.0mIU/L), T3 (100-200ng/dl), T4 (4.5$11.5 \mathrm{mg} / \mathrm{dl}$ ), thyroglobulin, anti-thyroglobulin antibody and FNAC of the thyroid nodule. The size of the nodule as measured by using $10 \mathrm{MHz}$ high frequency ultrasonographic probe is taken for analysis. Other investigations like contrast enhanced CT scan of the neck etc are left to the discretion of the clinician treating the patient. Based on the results of the FNAC a treatment plan is arrived and those who are undergoing surgery are further evaluated for fitness of surgery. A decision of hemi vs total thyroidectomy is made based primarily on the FNAC report and secondarily on the presenting clinical scenario.

The nodules where the preoperative FNAC was inconclusive (either suspicious or indeterminate) will be sent for frozen section at the time of surgery. All the specimen will be sent for permanent paraffin section. A detailed note of the number, clinical size of the nodule/largest nodule (as measured clinical and by ultrasound), presence of voice change, age and sex of the patient, results of the FNAC, frozen section and final histopathology along with biochemical information such as 1) preoperative thyroglobulin, 2) anti-TG antibody and 3) serum TSH will be made on Microsoft Excel spread sheet and factors will be analyzed. The further treatment and follow up of the patient will be decided as per the protocol of the departments based on the final histopathology.

\section{Inclusion criteria}

All patients presenting with thyroid nodules aged between 18-70 years willing to participate in the study.

\section{Exclusion criteria}

- Patients with poorly differentiated cytology, lymphoma or metastasis from elsewhere.

- Patients with FNAC or biopsy proven lymph node metastases, extra thyroidal invasion, and previous thyroid surgeries or recurrence.

- Patients who have undergone part of the treatment elsewhere.

- Patients with diffuse enlargement of the thyroid gland, primary and secondary thyrotoxicosis.

- Patients with frank clinical hypothyroidism.

\section{Statistical analysis}

Patients are grouped into benign or cancer group according to final diagnosis. Continuous variables are expressed as means \pm standard deviation, whereas categorical variables are presented as percentages. Differences between continuous variables were analyzed by unpaired Student's t-test or ANOVA and between categorical variables by chi-square test.

\section{RESULTS}

The 90 enrolled patients included 50 patients with thyroid carcinoma $(55.5 \%)$ and 40 patients with benign thyroid tumours $(44.5 \%)$. The mean age of the participants for malignant and benign tumour were $47 \pm 10.1$ and $45 \pm 9.2$ years, respectively. The majority of the patients were women ( $\mathrm{n}=71,78.8 \%)$, and malignancy was more common in female patients $(n=39,78 \%)$.

We detected a higher rate of malignant disease in patients with increased size of nodule such as $48 \%(1.01-4 \mathrm{~cm})$ and $40 \%(4.01-6.0 \mathrm{~cm})$, respectively.

Malignant tumours show high vascularity (62\%), calcification (46\%) and hypoechogenicity (60\%) than benign tumours on ultrasound (USG) (Table 1). 
Table 1: Characteristics of patients included in the study $(\mathrm{n}=90)$.

\begin{tabular}{|lll|}
\hline Variables & $\begin{array}{l}\text { Malignant group } \\
(\mathbf{n = 5 0})\end{array}$ & $\begin{array}{l}\text { Benign } \\
\text { group }(\mathbf{n = 4 0})\end{array}$ \\
\hline Mean age (yr) & $47 \pm 10.1$ & $45 \pm 9.2$ \\
\hline$<30$ & $4(8 \%)$ & $12(30 \%)$ \\
\hline $30-60$ & $35(70 \%)$ & $27(67.5 \%)$ \\
\hline$>60$ & $11(22 \%)$ & $1(2.5 \%)$ \\
\hline Gender & & \\
\hline Male & $11(22 \%)$ & $8(20 \%)$ \\
\hline Female & $39(78 \%)$ & $32(80 \%)$ \\
\hline Size of nodules & & \\
\hline$\leq 1$ cm & $1(2 \%)$ & $1(2.5 \%)$ \\
\hline $1.01-4$ cm & $24(48 \%)$ & $22(55 \%)$ \\
\hline $4.01-6.0$ cm & $20(40 \%)$ & $16(40 \%)$ \\
\hline$>6.0$ cm & $5(10 \%)$ & $1(2.5 \%)$ \\
\hline USG features & & \\
\hline Vascularity & $31(62 \%)$ & $17(42.5 \%)$ \\
\hline Calcification & $23(46 \%)$ & $16(40 \%)$ \\
\hline Hypoechogenic & $30(60 \%)$ & $18(45 \%)$ \\
\hline
\end{tabular}

Using ROC curve, the median thyroglobulin (TG) level in the malignant group was $94 \mathrm{ng} / \mathrm{ml}(0.01-700 \mathrm{ng} / \mathrm{ml})$ compared with $20 \mathrm{ng} / \mathrm{ml}(0.1-490 \mathrm{ng} / \mathrm{ml})$ in the benign group ( $p=0.014)$. A cut-off value of $36 \mathrm{mU} / \mathrm{L}$ had the highest sensitivity (62\%) and specificity (68\%) for diagnosing malignant disease (Figure 1).

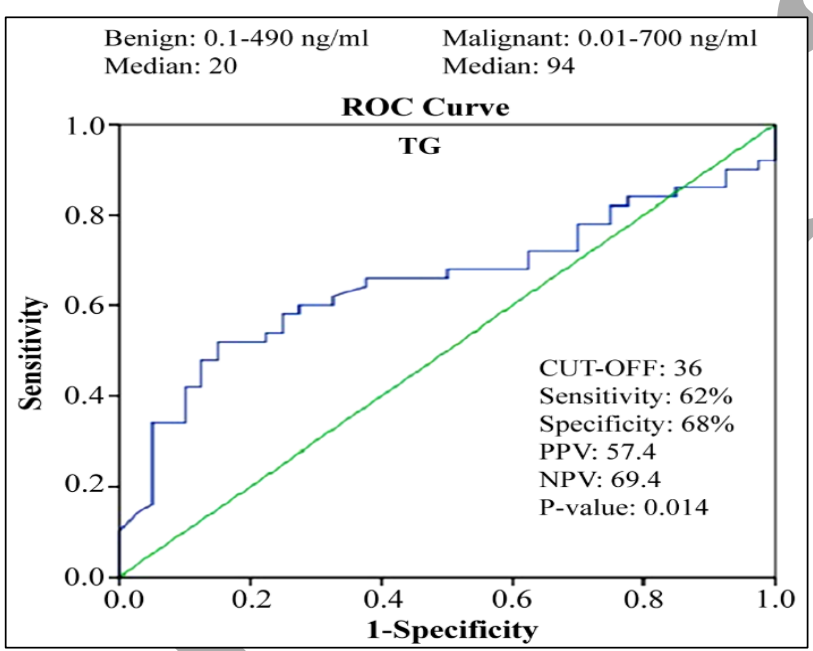

Figure 1: Thyroglobulin.

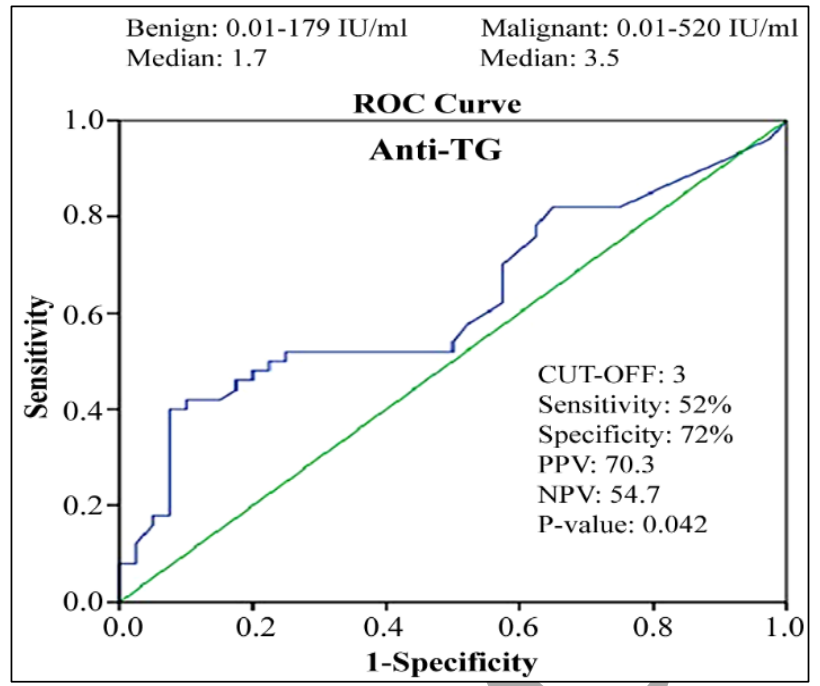

Figure 2: Anti-Thyroglobulin.

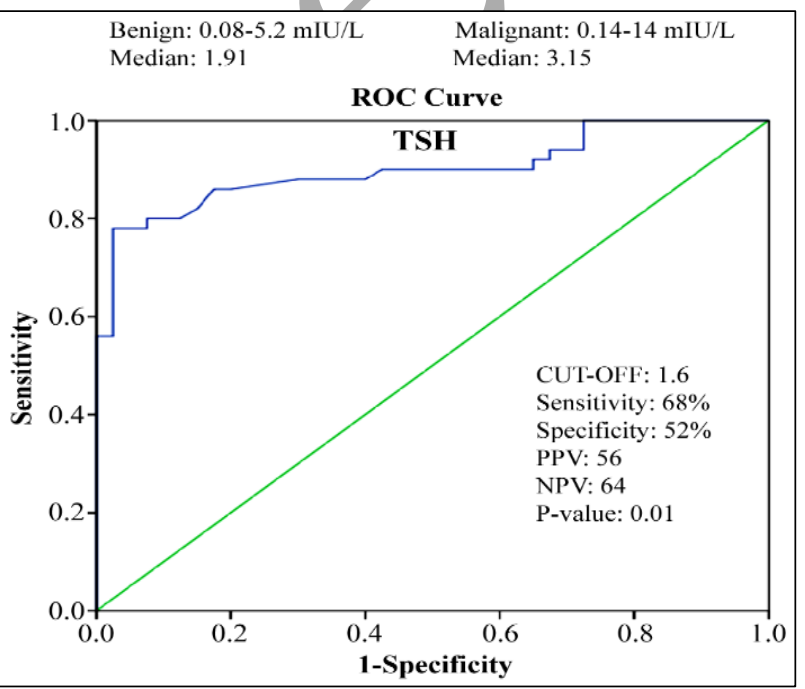

Figure 3: Thyroid stimulating hormone.

The median anti-thyroglobulin (Anti-TG) level in the malignant group was $3.5 \mathrm{IU} / \mathrm{ml} \quad(0.01-520 \mathrm{IU} / \mathrm{ml})$ compared with $1.7 \mathrm{IU} / \mathrm{ml}(0.01-179 \mathrm{IU} / \mathrm{ml})$ in the benign group ( $\mathrm{p}=0.042)$. A cut-off value of $3 \mathrm{mU} / \mathrm{L}$ had low sensitivity $(52 \%)$ and specificity $(72 \%)$ for diagnosing malignant disease. Both Pearson chi-square test $(\mathrm{p}<0.01)$ and Fisher's exact test $(\mathrm{p}<0.01)$ yielded statistical significance between the groups (Figure 2).

Table 2: Ultrasonography features.

\begin{tabular}{|llll|ll|}
\hline USG features & Sensitivity & Specificity & PPV & NPV & p value \\
\hline Vascularity & $62 \%$ & $57.5 \%$ & $64.6 \%$ & $54.8 \%$ & 0.06 \\
\hline Calcification & $46 \%$ & $60 \%$ & $59 \%$ & $47 \%$ & 0.56 \\
\hline Hypoechogenecity & $60 \%$ & $55 \%$ & $62.5 \%$ & $52.4 \%$ & 0.156 \\
\hline
\end{tabular}


The median TSH level in the malignant group was $3.15 \mathrm{mIU} / \mathrm{L}(0.14-14 \mathrm{mIU} / \mathrm{L})$, compared with $1.91 \mathrm{mIU} / \mathrm{L}$ $(0.08-5.2 \mathrm{mIU} / \mathrm{L})$ in the benign group $(\mathrm{p}=0.01)$. A cutoff value of $1.6 \mathrm{mU} / \mathrm{L}$ had the sensitivity $(68 \%)$ and specificity $(52 \%)$ for diagnosing malignant disease (Figure 3).

Diagnosis of malignancy based on vascularity has high sensitivity (62\%), positive predictive value (64.6\%) and negative predictive value $(54.8 \%)$ ( $\mathrm{p}$ value $=0.06)$ compared to other features such as calcification and hypoechogenicity on ultrasound (Table 2).

Table 3: Comparison between FNAC and HPE.

\begin{tabular}{|lll|}
\hline \multirow{2}{*}{ FNAC } & \multicolumn{2}{l|}{ Final HPE } \\
\hline Benign (40) & $27(67.5)$ & $13(32.5)$ \\
\hline Follicular neoplasm (6) & $2(33.3)$ & $4(66.7)$ \\
\hline Suspicious of malignancy (19) & $7(36.8)$ & $12(63.2)$ \\
\hline Malignancy (25) & $4(16)$ & $21(84)$ \\
\hline
\end{tabular}

Out of 40 benign nodules on FNAC, 13 (32\%) nodules were diagnosed as malignant on final histopathology after surgery. Among 19 suspicious cases of malignancy on FNAC, 12 (63.2\%) nodules were finally malignant after surgery. False positive rate: $26 \%$; false negative rate: $32 \%$ (Table 3 ).

Table 4: Comparison between Frozen and HPE.

\begin{tabular}{|c|c|}
\hline \multirow{2}{*}{ Frozen } & Final HPE \\
\hline & Benign Malignant \\
\hline Benign (11) & $5(45.5)-6(54.5)$ \\
\hline Suspicious of malignancy (4) & $1(25) \quad 3(75)$ \\
\hline Malignant (11) & $0(0) \quad 11(100)$ \\
\hline
\end{tabular}

Out of 11 benign nodules on frozen section, 6 (54.5\%) were diagnosed as malignant on final histopathological examination after surgery. Among 4 suspicious cases of malignancy on frozen section, 3 (75\%) nodules were finally malignant after surgery. Positive predictive value: 46\%; Negative predictive value: $73 \%$ (Table 4).

\section{DISCUSSION}

\section{Thyroglobulin $(\mathrm{Tg})$}

In the present study, sensitivity is comparable, and specificity is low when compared to other studies. Using ROC curve, with cut-off $\mathrm{Tg}>36 \mathrm{ng} / \mathrm{ml}$, we obtained $\mathrm{p}$ value of 0.014 . Both chi-square test $(p<0.01)$ and Fisher's exact test $(\mathrm{p}<0.01)$ yielded statistical significance. AntiTg comparison with other studies (Table 5)

- Kim et al, were first to report that a positive TgAb test is an independent predictor of thyroid cancer. ${ }^{9}$

- In another study by Hosseini et al. ${ }^{10}$
Table 5: Analysis of our study with other study.

\begin{tabular}{|lll|}
\hline & Hosseini et al & Present study \\
\hline No. of patients & 405 & 90 \\
\hline p-Value & 0.01 & 0.042 \\
\hline Cut-off & $30 \mathrm{IU} / \mathrm{ml}$ & $31 \mathrm{IU} / \mathrm{ml}$ \\
\hline Sensitivity & $16 \%$ & $52 \%$ \\
\hline Specificity & $90 \%$ & $72 \%$ \\
\hline PPV & $65.3 \%$ & $56 \%$ \\
\hline NPV & $49.5 \%$ & $64 \%$ \\
\hline
\end{tabular}

There are very few studies on role of anti-Tg $\mathrm{Ab}$ in preoperative evaluation. With cut-off of $3 \mathrm{IU} / \mathrm{ml}$, we obtained $\mathrm{p}$ value of 0.042 . In present study, sensitivity and specificity are low. Both Pearson chi-square test $(\mathrm{p}<0.01)$ and Fisher's exact test $(\mathrm{p}<0.01)$ yielded statistical significance between the groups.

\section{TSH}

- A study by Zeng et al, on 108 patients reported that preoperative TSH level may be useful in predicting cancer in thyroid nodules. Mean TSH in malignant vs benign nodules are 1.94 vs $1.16 \mathrm{mIU} / \mathrm{L}$ (p $<0.005) .{ }^{11}$

- Another study by Jin et al, on 653 patients, mean $\mathrm{TSH}$ in malignant and benign groups are $5.5 \mathrm{vs}$ $1.4 \mathrm{mIU} / \mathrm{L}(\mathrm{p}=0.001) .^{12}$

- In the present study, mean TSH in malignant and benign nodules are 3.15 vs $1.91 \mathrm{mIU} / \mathrm{L}$ sensitivity, specificity and $\mathrm{p}$ value are $68 \%, 52 \%$ and $\mathrm{p}=0.001$.

\section{USG features}

Recently ultrasound has been suggested as a a valuable aid to enhance FNAC diagnostic performance. ${ }^{13}$ In a meta-analysis of 52 studies on 12,786 nodules done by Remonti et al concluded that all USG features are associated with malignancy with an odds ratio varying from $1.78-35.6 .^{14}$

\section{FNAC vs HPE}

Sensitivity and specificity for FNAC in published series range about $65-98 \%$ and $73-100 \%$ respectively. FNAC is safe, accurate, and cost-effective. It is used as initial diagnostic test. ${ }^{15}$ Recently, ultrasound guidance has been suggested as a valuable aid to enhance FNAC diagnostic performance. ${ }^{16}$ FNAC should be undertaken with ultrasound guidance and if possible with a pathologist in attendance to assess sample adequacy. We recommend a high index of suspicion of thyroid cancer in the male patient who presents with a solitary nodule. ${ }^{17}$

FNAC is a highly effective method for identifying those patients with thyroid enlargement who require surgery because of the presence of malignancy. We have 
demonstrated that the serum TSH concentration at presentation, even when within the normal range, is an independent predictor of the presence of thyroid malignancy. Our study confirms that patients' gender and age, as well as the size of nodule, are further independent predictors of the presence of thyroid malignancy. In a study by Bagga and Mahajan, FNAC showed a sensitivity of $66 \%$ and specificity of $100 \%$. In a study by Sinna and Ezzat on 98 cases, FNAC showed a sensitivity of $93 \%$, specificity of $94 \%$, PPV of $95 \%$, NPV of $92 \% .^{18,19}$ In the present study sensitivity is $74 \%$ and specificity is $67 \%$ (Table 6).

Major reason for wide range of sensitivity and specificity among studies is difference in categorization of follicular neoplasm and suspicious of malignancy. Other factors that decrease efficacy are inadequate sampling due to calcified nodules and inexperienced cytologist.

Table 6: Further analysis of the present study with other study group.

\begin{tabular}{|llllll|}
\hline & Sensitivity & Specificity & PPV & NPV & Accuracy \\
\hline Muratli et al $^{20}$ & 65 & 87 & 76 & 90 & 92 \\
\hline Mahar et al $^{21}$ & 98 & 70 & 91 & 93 & 92 \\
\hline${\text { Haberal et } \mathrm{al}^{22}}$ & 93 & 91 & 83 & 96 & 92 \\
\hline Present study & 74 & 67 & 74 & 67 \\
\hline
\end{tabular}

In the present study, out of 40 benign nodules on FNAC, $13(32 \%)$ nodules are diagnosed as malignant on final histopathology after surgery.

Out of 19 cases of suspicious of malignancy on FNAC, $12(63 \%)$ nodules are finally malignant. False positive rate: $26 \%$; false negative rate: $32 \%$. In Muratli et al, FP: $7.3 \%$; FN: $15 \% .^{20}$ In other studies, it ranges: FP: $1-11 \%$; FN: $1-7 \%$.

Common reasons for false positives are follicular lesions and lesions that are suspicious of malignancy.

Table 7: Changed management strategy after final HPE.

\begin{tabular}{|llll|}
\hline Frozen & Total & \multicolumn{2}{l|}{ Final HPE } \\
\cline { 2 - 4 } & Benign & Malignant \\
\hline Benign & 11 & 5 & 6 \\
\hline $\begin{array}{l}\text { Suspicious of } \\
\text { malignancy }\end{array}$ & 4 & 1 & 3 \\
\hline Malignant & 11 & 0 & 11 \\
\hline
\end{tabular}

Table 8: Comparison with other study by specificity and sensitivity.

\begin{tabular}{|lll|}
\hline & Guevara et $^{\mathbf{2 3}}$ & Present study \\
\hline Specificity & 100 & 80 \\
\hline Sensitivity & 75 & 75 \\
\hline PPV & 100 & 94 \\
\hline NPV & 95 & 46 \\
\hline Accuracy & 95 & 73 \\
\hline
\end{tabular}

In the present study, out of $13 \mathrm{FP}, 7$ cases are due to suspicious lesions. In the present study, false negative rate is high-32\% and specificity is less when compared to other studies. High false negative rate of FNAC may lead to misdiagnosis of a malignant nodule as benign (Table 7). In the present study, out of 26 frozen section cases, it changed management strategy in 11 cases.

Out of 11 cases of malignant nodules on frozen and HPE, 2 are reported as benign and 9 cases were reported as indeterminate nodules on FNAC (Table 8). Guevara et al, concluded that when is frozen section complimentary to FNAC, it allows immediate individual optimization of surgery intraoperatively. ${ }^{23}$

In the present study, specificity and sensitivity are in the range of other studies. But accuracy is less when compared to other studies.

\section{CONCLUSION}

Preoperative $\mathrm{Tg}$ with cut-off $>36 \mathrm{ng} / \mathrm{ml}$ is a significant predictor of malignancy. Anti-Tg Ab with cut-off of 3 $\mathrm{IU} / \mathrm{ml}$ along with TSH are independent predictors of malignancy. None of the USG features showed significance in predicting malignancy. FNAC and FROZEN has specificity of 67 and $75 \%$ and sensitivity of 74 and $80 \%$, respectively. Accuracy of FNAC and FROZEN are 71 and $73 \%$. Further prospective studies are needed to evaluate role of these biochemical factors as predictors of malignancy.

Funding: No funding sources

Conflict of interest: None declared

Ethical approval: The study was approved by the Institutional Ethics Committee

\section{REFERENCES}

1. British Thyroid Association, Royal College of Physicians. British Thyroid Association Guidelines for the Management of Thyroid Cancer. 2007. 
Available at: http://www.british-thyroidassociation.org

2. Datta RV, Petrelli NJ, Ramzy J. Evaluation and management of incidentally discovered thyroid nodules. Surgical Oncol. 2006;15:33-42.

3. Cooper DS, Doherty GM, Haugen BR, Kloos RT, Lee SL, Mandel SJ, et al. Management guidelines for patients with thyroid nodules and differentiated thyroid cancer. The American Thyroid Association Guidelines Taskforce. Thyroid. 2006;16:109-42.

4. Khan SA, Gafur MA, Khan MK, Karim MR, Mohiuddin M, Islam MS. Pattern of malignancy in clinically solitary thyroid nodule. Mymensingh Med J. 2012;21:1-7.

5. Pinchera A, Aghini-Lombardi F, Antonangeli L, Vitti P. Multinodular goiter. Epidemiology and prevention. Annali Italiani di Chirurgia, 1996;67:317-25.

6. Papini E, Guglielmi R, Bianchini A, Crescenzi A, Taccogna S, Nardi F, et al. Risk of malignancy in nonpalpable thyroid nodules: predictive value of ultrasound and color-Doppler features. J Clin Endocrinol Metabol. 2002;87:1941-6.

7. Frates MC, Benson CB, Doubilet PM, Kunreuther E, Contreras M, Cibas ES, et al. Prevalence and distribution of carcinoma in patients with solitary and multiple thyroid nodules on sonography. J Clin Endocrinol Metabol. 2006;91:3411-7.

8. Okayasu I, Fujiwara M, Hara Y, Tanaka Y, Rose NR. Association of chronic lymphocytic thyroiditis and thyroid papillary carcinoma. A study of surgical cases among Japanese, and white and African Americans. Cancer. 1995;76:2312-8.

9. Kim HJ, Mok JO, Kim CH, Kim YJ, Kim SJ, Park $\mathrm{HK}$, et al. Preoperative serum thyroglobulin and changes in serum thyroglobulin during $\mathrm{TSH}$ suppression independently predict follicular thyroid carcinoma in thyroid nodules with a cytological diagnosis of follicular lesion. Endocrine Res. 2017;42:154-62.

10. Hosseini S, Payne RJ, Zawawi F, Mlynarek A, Hier MP, Tamilia M, et al. Can preoperative thyroglobulin antibody levels be used as a marker for well differentiated thyroid cancer? J Otolaryngol-Head Neck Surg. 2016;45:31.

11. Zeng Q, Liu J, Zhu J, Hu G. Association between preoperative serum thyroid-stimulating hormone level and non-functioning malignant nodule thyroid disease. Lin Chung Er Bi Yan Hou Tou Jing Wai Ke Za Zhi. 2014;28:1931-3.

12. Jin J, Machekano R, McHenry CR. The utility of preoperative serum thyroid-stimulating hormone level for predicting malignant nodular thyroid disease. Am J Surg. 2010;199:294-8.

13. Morgan JL, Serpell JW, Cheng MS. Fine-needle aspiration cytology of thyroid nodules: how useful is it? ANZ J Surg. 2003;73:480-3.

14. Remonti LR, Kramer CK, Leitao CB, Pinto LC, Gross JL. Thyroid ultrasound features and risk of carcinoma: a systematic review and meta-analysis of observational studies. Thyroid. 2015;25:538-50.

15. Nieto $H$, Boelaert $K$. Women in cancer thematic review: thyroid-stimulating hormone in thyroid cancer: does it matter? Endocrine-Related Cancer. 2016;23:T109-21.

16. Danese D, Sciacchitano S, Farsetti A, Andreoli M, Pontecorvi A. Diagnostic accuracy of conventional versus sonography-guided fine-needle aspiration biopsy of thyroid nodules. Thyroid. 1998;8:15-21.

17. Gharib H, Goellner JR. Fine-needle aspiration biopsy of the thyroid: an appraisal. Ann Internal Med. 1993;118:282-9.

18. Bagga PK, Mahajan NC. Fine needle aspiration cytology of thyroid swellings: How useful and accurate is it? Indian J Cancer. 2010;47:437-42.

19. Sinna EA, Ezzat N. Diagnostic accuracy of fine needle aspiration cytology in thyroid lesions. J Egyp National Cancer Institute. 2012;24:63-70.

20. Muratli A, Erdogan N, Sevim S, Unal I, Akyuz S. Diagnostic efficacy and importance of fine-needle aspiration cytology of thyroid nodules. J Cytol. 2014;31:73-8.

21. Mahar SA, Husain A, Islam N. Fine needle aspiration cytology of thyroid nodule: diagnostic accuracy and pitfalls. J Ayub Med Coll Abbottabad. 2006;18:26-9.

22. Haberal AN, Toru S, Ozen O, Arat Z, Bilezikci B. Diagnostic pitfalls in the evaluation of fine needle aspiration cytology of the thyroid: Correlation with histopathology in 260 cases. Cytopathol. 2009;20:103-8.

23. Guevara N, Lassalle S, Benaim G, Sadoul JL, Santini J, Hofman P. Role of frozen section analysis in nodular thyroid pathology. Eur Ann Otorhinolaryngol Head Neck Dis. 2015;132:67-70.

Cite this article as: Umapathy $\mathrm{P}$, Swaminathan GA, Farshana MF, Devagi M. A study of predictive factors of malignancy in thyroid nodules. Int Surg J 2018;5:3817-22. 